\title{
Gold Nanobeads with Enhanced Absorbance for Improved Sensitivity in Competitive Lateral Flow Immunoassays
}

\author{
Xirui Chen ${ }^{1,2}$, Xintao Miao ${ }^{1,2}$, Tongtong Ma ${ }^{1,2}$, Yuankui Leng ${ }^{1,2}$, Liangwen Hao ${ }^{1,2}$, Hong Duan ${ }^{1,2}$, Jing Yuan ${ }^{1,2}$, \\ $\mathrm{Yu} \mathrm{Li}^{1,2}$, Xiaolin Huang $1,2, * \mathbb{D}$ and Yonghua Xiong ${ }^{1,2,3}$ \\ 1 State Key Laboratory of Food Science and Technology, Nanchang University, Nanchang 330047, China; \\ cxirui219921@163.com (X.C.); 7901118101@email.ncu.edu.cn (X.M.); 13879123712@163.com (T.M.); \\ yuankuilengxq@163.com (Y.L.); 2010633@tongji.edu.cn (L.H.); duanhong202@163.com (H.D.); \\ yuan.jing@cau.edu.cn (J.Y.); 15083528053@163.com (Y.L.); xiongyonghua@ncu.edu.cn (Y.X.) \\ 2 School of Food Science and Technology, Nanchang University, Nanchang 330047, China \\ 3 Jiangxi-OAI Joint Research Institute, Nanchang University, Nanchang 330047, China \\ * Correspondence: xiaolin.huang@ncu.edu.cn
}

check for updates

Citation: Chen, X.; Miao, X.; Ma, T.; Leng, Y.; Hao, L.; Duan, H.; Yuan, J.; Li, Y.; Huang, X.; Xiong, Y. Gold

Nanobeads with Enhanced

Absorbance for Improved Sensitivity in Competitive Lateral Flow Immunoassays. Foods 2021, 10, 1488. https://doi.org/10.3390/

foods 10071488

Academic Editor: Philippe Delahaut

Received: 26 May 2021

Accepted: 24 June 2021

Published: 27 June 2021

Publisher's Note: MDPI stays neutral with regard to jurisdictional claims in published maps and institutional affiliations.

Copyright: (c) 2021 by the authors. Licensee MDPI, Basel, Switzerland. This article is an open access article distributed under the terms and conditions of the Creative Commons Attribution (CC BY) license (https:// creativecommons.org/licenses/by/ $4.0 /)$.

\begin{abstract}
Background: Colloidal gold based lateral flow immunoassay (LFIA) commonly suffers from relatively low detection sensitivity due to the insufficient brightness of conventional gold nanoparticles (AuNPs) with the size of 20-40 nm. Methods: Herein, three kinds of gold nanobeads (GNBs) with the size of $94 \mathrm{~nm}, 129 \mathrm{~nm}$, and $237 \mathrm{~nm}$, were synthesized by encapsulating numerous hydrophobic AuNPs $(10 \mathrm{~nm})$ into polymer matrix. The synthesized GNBs exhibited the enhanced colorimetric signal intensity compared with 20-40 nm AuNPs. The effects of the size of GNBs on the sensitivity of LFIA with competitive format were assessed. Results: The results showed that the LFIA using $129 \mathrm{~nm}$ GNBs as amplified signal probes exhibits the best sensitivity for fumonisin $\mathrm{B}_{1}$ $\left(\mathrm{FB}_{1}\right)$ detection with a cut-off limit (for visual qualitative detection) at $125 \mathrm{ng} / \mathrm{mL}$, a half maximal inhibitory concentration at $11.27 \mathrm{ng} / \mathrm{mL}$, and a detection limit at $1.76 \mathrm{ng} / \mathrm{mL}$ for detection of real corn samples, which are 8-, 3.82-, and 2.89-fold better than those of conventional $\mathrm{AuNP}_{40}$-based LFIA, respectively. The developed GNB-LFIA exhibited negligible cross-reactions with other common mycotoxins. In addition, the accuracy, precision, reliability, and practicability were demonstrated by determining real corn samples. Conclusions: All in all, the proposed study provides a promising strategy to enhance the sensitivity of competitive LFIA via using the GNBs as amplified signal probes.
\end{abstract}

Keywords: gold nanobeads; lateral flow immunoassay; enhanced sensitivity; mycotoxin; corn sample

\section{Introduction}

Colloidal gold based lateral flow immunoassay (LFIA) is one of the most popular screening tools for on-site bio-detection by the naked-eye because of its advantages, such as simplicity, convenience, rapidity, and low cost [1,2]. For the conventional LFIA, the presence of a red band in the detection line depends on the sufficient gold nanoparticle (AuNP) accumulation [3]. In competitive format, an evident red band at the test line is required when target analytes are absent in the sample solution. Thus, the presence of sufficient AuNPs on the test line is the premise to produce a distinct red band. The color intensity of accumulated AuNPs is associated with the accumulation number and the original color intensity of AuNPs [4]. However, conventional 20-40 nm AuNPs suffer from relatively weak color intensity, thus indicating the need for their increasing accumulation to generate an apparent red band in the test zone [5]. However, an increased AuNP number is non-conducive to the competition inhibition of target analytes and thus leads to decreased sensitivity. Theoretically, improving the color intensity of individual probes can effectively reduce the required number of accumulated probes in the test area for enhanced sensitivity in competitive LFIA. For this purpose, various new nanomaterials with enhanced signal 
transducer features, such as quantum dots (QDs) [6], upconversion nanoparticles [7], dyedoped nanoparticles [8], and magnetic nanobeads [9], have been recently introduced to replace AuNPs as LFIA labels to improve the sensitivity. Nonetheless, external excitation and advanced reading devices are necessary for signal acquisition, thereby partially limiting the potential of such nanomaterials in field detection. Thus, the simultaneous enhancement of color signal intensity and the naked-eye-based visual detection capability of conventional AuNP-based colorimetric probes remains a huge challenge.

Nanocontainers are versatile structures containing a considerable number of cavities, holes, or pores that can be applied for loading various materials, such as drugs, enzymes, nanoparticles, and signal-generating molecules [10-12]. At present, the available nanocontainers mainly involve liposomes [13], mesoporous silica [12], proteinsomes [14], and polymer- [15], metal oxide- [16], and carbon-based nanomaterials [17]. The large surface areas and inner volumes of such nanocontainers endow them with superior loading capacity to entrap diverse molecules for wide-ranging applications in drug delivery, bioimaging, bioreactors, and biodetection [18-22]. Polymer nanocontainers, such as polymersomes or polymeric nanocapsules, have attracted increasing interest in the signal amplification systems due to their excellent water solubility, biocompatibility, and colloid stability [23]. On the other hand, polymer nanocontainers are readily synthesized using various methods, including self-assembly-based strategies [24], film hydration methods [25], phase-separation techniques [26], and template polymerization approaches [27,28]. For example, our previous studies reported polymer-based nanocontainers for the encapsulation of highly luminescent CdSe/ZnS QDs by using the self-assembly method [29]. Numerous isolated QDs were tightly embedded in the polymeric nanocapsules. The obtained QD-encapsulated nanocontainers revealed 2863-fold higher luminescent intensity than the original individual QDs. We demonstrated the feasibility of using these QD nanocontainers as enhanced signal reporters in conventional competitive LFIA to improve sensitivity owing to their ultrahigh luminescent signal.

On this basis, herein, we first fabricated a polymer-based nanocontainer for the encapsulation of small size AuNPs to prepare large size gold nanobeads (GNBs) with significantly enhanced absorbance [30]. We also demonstrated the potential of GNBs as amplified labeling probes in competitive LFIA for increased sensitivity. The GNBs were synthesized by encapsulating numerous isolated hydrophobic AuNPs $(10 \mathrm{~nm})$ into a polymer matrix of poly (maleicanhydride-alt-1-octadecene) (PMAO) by using the emulsionbased self-assembly strategy. The PMAO matrix was selected as a polymer layer because it can increase the interparticle gap for decreased plasmonic coupling and provide the carboxyl surface for subsequent biomolecule functionalization. Further characterization indicated that the resultant GNBs exhibited a uniform regular sphere with numerous AuNPs internally distributed. The number of embedded AuNPs and the absorbance were tuned by changing the GNB size, providing an opportunity to better investigate the relationship between the GNB size and the analytical performance of LFIA because the GNB size can affect the LFIA sensitivity by influencing the signal intensity and the immunological reaction efficiency [31].

Contamination of cereals and related products by mycotoxins has become an increasingly serious food safety problem. As a common mycotoxin, fumonisins (FBs) are nephrotoxic, hepatotoxic, and carcinogenic mycotoxins mainly produced by Fusarium mold species. Among all known $\mathrm{FBs}, \mathrm{FB}_{1}$ almost constitutes about $70 \%$ found in contaminated foods. Given its high threat to human and animal health, $\mathrm{FB}_{1}$ has been regarded as a human group 2B carcinogen by the International Agency for Research on Cancer [32-35]. Hence, the rapid and sensitive detection of $\mathrm{FB}_{1}$ for food industry is critical to minimize its hazards. Under the optimal condition, the GNBs with size of $129 \mathrm{~nm}\left(\mathrm{GNB}_{129}\right)$ as the signal reporter of LFIA featured a high sensitivity in detecting $\mathrm{FB}_{1}$. The cut-off limit (for visual qualitative detection), half maximum inhibitory concentration, and detection limit (for quantitative analysis) of $\mathrm{GNB}_{129}$-LFIA were $125 \mathrm{ng} / \mathrm{mL}, 11.27$, and $1.76 \mathrm{ng} / \mathrm{mL}$, which were 8-, 3.82-, and 2.89-fold lower than conventional LFIA strip with $40 \mathrm{~nm}$ AuNPs $\left(\mathrm{AuNP}_{40}\right)$ as 
labeling probes. The specificity, accuracy, reproducibility, reliability, and practicability of our proposed $\mathrm{GNB}_{129}$-LFIA were demonstrated in real corn samples. In conclusion, the designed GNBs can act as a promising signal reporter in LFIA to provide an amplified competitive detection for various small molecular chemicals, such as mycotoxins.

\section{Materials and Methods}

2.1. Materials and Reagents

Aflatoxin $B_{1}\left(\mathrm{AFB}_{1}\right)$, aflatoxin $\mathrm{B}_{2}\left(\mathrm{AFB}_{2}\right)$, aflatoxin $\mathrm{G}_{1}\left(\mathrm{AFG}_{1}\right)$, zearalenone (ZEN), citrinin (CIT), $\mathrm{FB}_{1}$, and ochratoxin $\mathrm{A}$ (OTA) were purchased from Huaan Magnech Bio-Tech Co., Ltd. (Beijing, China). Oleylamine, sodium dodecyl sulfonate (SDS), gold(III) chloride hydrate, trisodium citrate $\left(\mathrm{Na}_{3} \mathrm{C}_{6} \mathrm{H}_{5} \mathrm{O}_{7} \cdot 2 \mathrm{H}_{2} \mathrm{O}\right)$, bovine serum albumin (BSA), 1-ethyl-3- (3dimethylaminopropyl) carbodiimide (EDC), and poly (maleicanhydride-alt-1-octadecene) (PMAO, MW = 30,000 50,000 Da) were obtained from Sigma-Aldrich (St. Louis, MO, USA). Anti-FB ${ }_{1}$ monoclonal antibodies (mAbs) were kindly provided by prof. Yang $\mathrm{Xu}$ from Nanchang University (Nanchang, China). The BSA-FB 1 conjugates (molar ratio of 1:23) were prepared by our laboratory. The sample pad, the absorbent pad, and the NC membrane were provided by Wuxi Zodolabs Biotech Co., Ltd. (Jiangsu, China). Goat antimouse IgG was obtained from Chongqing Xinyuanjiahe Biotechnology Inc. (Chongqing, China). Other chemicals were of analytical grade and purchased from Sinopharm Chemical Corp. (Shanghai, China). All reagents were used without further purification.

\subsection{Characterization}

The morphology and structure of the prepared GNBs were investigated using a JEOL JEM 2100 transmission electron microscope (TEM, Tokyo, Japan). Dynamic light scattering (DLS) analysis was performed using a Zetasizer Nano-ZEN3700 instrument (Malvern, UK) to determine the size distribution of various GNBs. Ultraviolet-visible (UV-Vis) absorption spectra were obtained using an Amersham Pharmacia Ultrospec 4300 pro UV/visible spectrophotometer (England, UK). Real corn samples were firmed by using a LC-Q/TOF MS instrument (Agilengt 1290-6538, Palo Alto, CA, USA).

\subsection{Synthesis of Hydrophobic AuNPs}

Hydrophobic AuNPs with a size of $10 \mathrm{~nm}$ were prepared following a previous report [36]. In a typical synthesis procedure, gold(III) chloride hydrate $(0.3 \mathrm{mmol})$ was dissolved in a mixed solution of oleylamine $(7.4 \mathrm{mmol})$ and chloroform $(1.0 \mathrm{~mL})$ under magnetic stirring. The above-mentioned mixture was quickly added to $49 \mathrm{~mL}$ boiling chloroform solution containing $35.3 \mathrm{mmol}$ oleylamine. After approximately $10 \mathrm{~min}$, the color of the reaction solution became deep red. After continuous reaction for $3 \mathrm{~h}$, the synthesized AuNPs were then collected by adding $50 \mathrm{~mL}$ ethanol. Finally, the hydrophobic AuNPs were stored in chloroform for further use.

\subsection{Synthesis of Carboxylated GNBs}

$\mathrm{GNB}_{129}$ was prepared according to a previous work with a slight modification [30]. In a typical synthesis procedure, a $50 \mu \mathrm{L}$ chloroform solution containing hydrophobic AuNPs (10 mg) and PMAO ( $2 \mathrm{mg})$ was added into $500 \mu \mathrm{L}$ sodium dodecyl sulfate (SDS) solution $(12 \mathrm{mg} / \mathrm{mL})$, followed by ultrasonication for $2 \mathrm{~min}$ under $76.8 \mathrm{~W}$ ultrasonic power to produce an oil-in-water microemulsion. After the evaporation of chloroform at $60^{\circ} \mathrm{C}$ for $2 \mathrm{~h}$, the synthesized $\mathrm{GNB}_{129}$ was centrifuged and then re-suspended in $0.01 \mathrm{M}$ phosphate buffer (PB, pH 10) for $24 \mathrm{~h}$ to hydrolyze the anhydride group of PMAO into the carboxyl group. Finally, the resultant carboxylated $\mathrm{GNB}_{129}$ was centrifuged and washed thrice with water. Similar synthesis procedures were conducted for preparing $\mathrm{GNB}_{94}$ and $\mathrm{GNB}_{237}$ but with alteration of the SDS amount and the volume ratio of oil/water (Table S1). 


\subsection{Synthesis of Anti-FB1 Monoclonal Antibodies Labeled $G B_{129}$ (GNB $\left.{ }_{129}-m A b s\right)$}

$\mathrm{GNB}_{129}-\mathrm{mAbs}$ were prepared through the formation of a peptide bond between the carboxyl group of $\mathrm{GNB}_{129}$ and the amino group of antibodies by using the active ester method. Approximately $1 \mu \mathrm{L}$ anti-FB ${ }_{1}$ mAbs $(6.4 \mathrm{mg} / \mathrm{mL})$ was added into $400 \mu \mathrm{L}$ $0.01 \mathrm{M} \mathrm{pH} 6.5$ phosphate buffer $(\mathrm{PB})$ solution containing $\mathrm{GNB}_{129}(0.14 \mathrm{pM})$ and 1-ethyl-3(3-dimethylamino) propyl carbodiimide (EDC) $(1 \mu \mathrm{g})$. The mixed solution was incubated for $90 \mathrm{~min}$ at room temperature. Subsequently, $10 \mathrm{mg}$ BSA was added into the mixture solution for another $1 \mathrm{~h}$ of reaction. The synthesized $\mathrm{GNB}_{129}-\mathrm{mAbs}$ were then centrifuged and resuspended in $200 \mu \mathrm{L} 0.01 \mathrm{M} \mathrm{PB}(\mathrm{pH} 7.4$ ) containing $25 \%$ sucrose, $1 \%$ bovine serum albumin (BSA), and $0.1 \%$ sodium azide.

\subsection{Preparation of $B S A-F B_{1}$ Conjugate}

The BSA-FB ${ }_{1}$ conjugate was synthesized according to a previous work with minor modification [37]. In brief, $0.5 \mathrm{mg}$ of $\mathrm{FB}_{1}$ and $3 \mathrm{mg}$ of $\mathrm{BSA}$ were dissolved in $500 \mu \mathrm{L}$ of MES buffer solution (molar ratio of $\mathrm{FB}_{1}$ to BSA is 15:1). About $0.2 \mathrm{mg}$ of EDC was added to the mixture, then the mixture was incubated on a shaker at room temperature for $1 \mathrm{~h}$. Unreacted EDC and $\mathrm{FB}_{1}$ were removed via $3 \mathrm{~d}$ of dialysis in $1 \mathrm{~L}$ of $0.01 \mathrm{M}$ PBS (pH 7.4). The final BSA-FB 1 solution was collected, added with glycerin at the final concentration of $50 \%$, and then stored in a refrigerator at $-20{ }^{\circ} \mathrm{C}$.

\subsection{Construction of $G N B_{129}$-LFIA Test Strips}

The $\mathrm{GNB}_{129}$-LFIA test strips were constructed according to our previous report with

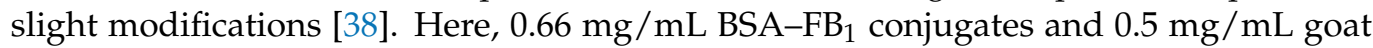
anti-mouse IgG were sprayed onto the nitrocellulose (NC) membrane as the test $(\mathrm{T})$ and control (C) lines at the density of $0.6 \mathrm{~mL} / \mathrm{cm}$ on a ZX1000 dispensing platform. The distance between two lines was $6.0 \mathrm{~mm}$. The NC membrane was then vacuum-dried overnight at $37^{\circ} \mathrm{C}$. The other operations are the same.

\subsection{Quantitative Procedure of GNB-LFIA for $F B_{1}$ Detection}

Approximately $2 \mu \mathrm{L} \mathrm{GNB}_{129}-\mathrm{mAb}$ probes $(0.34 \mathrm{fmol})$ were premixed with $70 \mu \mathrm{L}$ sample standard solutions containing a series of different concentrations of $\mathrm{FB}_{1}$ for incubation of $5 \mathrm{~min}$. The mixture solution was then added to the sample well of the assembled strip. After reaction for $15 \mathrm{~min}$, the optical intensities at the $\mathrm{T}$ and $\mathrm{C}$ lines $\left(\mathrm{OD}_{\mathrm{T}}\right.$ and $\mathrm{OD}_{\mathrm{C}}$, respectively) were recorded using a commercial HG-8 colloidal gold strip reader. The competitive inhibition curve was established by plotting the inhibition rate $\left(\mathrm{B} / \mathrm{B}_{0} \times 100 \%\right)$ against the logarithm $\mathrm{FB}_{1}$ concentrations, where $\mathrm{B}_{0}$ and $\mathrm{B}$ represent the $\mathrm{OD}_{\mathrm{T}} / \mathrm{OD}_{\mathrm{C}}$ values of negative and positive samples, respectively.

\subsection{Sample Preparation}

Real corn samples without $\mathrm{FB}_{1}$ as confirmed by the liquid chromatography-mass spectrometry were purchased from the local supermarket. Briefly, the sample preparation and chromatography-mass spectrometry operation were performed according to the national standard GB5009.240-2016 (China). Thereafter, all the corn samples were spiked with $\mathrm{FB}_{1}$ at a concentration ranging from $0.5 \mathrm{mg} / \mathrm{kg}$ to $10 \mathrm{mg} / \mathrm{kg}$ to evaluate the practicality of our designed $\mathrm{GNB}_{129}$-LFIA. Prior to LFIA detection, the $\mathrm{FB}_{1}$ extraction was conducted as follows: $5.0 \mathrm{~g} \mathrm{FB}_{1}$-contaminated pulverized corn sample was extracted with $4 \mathrm{~mL}$ methanol-water $(60: 40, v / v)$ for $20 \mathrm{~min}$ on a vortex shaker. After centrifugation at $16,000 \mathrm{rpm}$ for $15 \mathrm{~min}$, the supernatant was stored at $-20^{\circ} \mathrm{C}$ and further diluted by 12 -fold with $0.01 \mathrm{M} \mathrm{pH}$ 7.4 PB solution prior to analysis. To estimate the reliability of our method, we performed a correlation analysis between our $\mathrm{GNB}_{129}$-LFIA strip method and conventional enzyme-linked immunosorbent assay (ELISA) by simultaneously testing 35 real corn samples, with the $\mathrm{FB}_{1}$ concentration ranging from $1.5 \mathrm{ng} / \mathrm{mL}$ to $267 \mathrm{ng} / \mathrm{mL}$ by using two approaches. 


\section{Results and Discussion}

\subsection{Synthesis and Characterization of GNBs}

The GNBs were synthesized through the microemulsion-based self-assembly strategy. Figure 1a depicts the detailed synthetic procedure. Oleylamine-capped AuNPs (OA-AuNPs) with a size of $10 \mathrm{~nm}$ (Figure S1) were synthesized and used as building blocks for the self-assembled synthesis of GNBs. A mixed solution of OA-AuNPs and PMAO dissolved in chloroform was added to the SDS solution, followed by ultrasonic emulsification. The assembled GNBs were obtained with the evaporation of chloroform. Different sizes of GNBs were achieved by changing the SDS amount and the volume ratio of oil/water (Table S1). The resultant GNBs were then characterized by transmission electron microscopy (TEM), dynamic light scattering (DLS), and ultraviolet-visible (UVvis) absorption spectra. The TEM images (Figure 1b) showed that all three assembled GNBs exhibited regular spheres measuring $94 \pm 13,129 \pm 17$, and $237 \pm 21 \mathrm{~nm}$, these values are slightly smaller than the hydrodynamic diameters measured by DLS (inset in Figure 1b), which were $98 \pm 8,144 \pm 12$, and $253 \pm 16 \mathrm{~nm}$, respectively. This variation may be due to the low contrast of the PMAO polymer layer on the GNB surface in TEM imaging. The magnified TEM image in the inset of Figure $1 \mathrm{~b}$ indicates that numerous isolated AuNPs were successfully encapsulated into the polymer matrix. The embedded AuNP number increased with the increase in the GNB sizes. Figure 1c demonstrates that the UV-vis absorption spectra of the three GNBs obtained at the same particle concentration displayed the size-dependent increase in absorbance. The absorbance of $\mathrm{GNB}_{94}, \mathrm{GNB}_{129}$, and $\mathrm{GNB}_{237}$ provided a 1.3-, 3.7-, and 17.7-fold enhancement compared with $\mathrm{AuNP}_{40}$. A red shift of GNBs from $542 \mathrm{~nm}$ to $556 \mathrm{~nm}$ was also observed, along with an evident color change from red to amaranth that is also suitable for the naked-eye-based detection (inset of Figure 1c). This result demonstrated that GNBs can provide a significant enhancement in absorbance but without compromising the naked-eye-based detection capability. GNBs of three sizes were sprayed onto the NC membrane as the T line to study their effect on the OD at the T area. The widely used $\mathrm{AuNP}_{40}$ at the same particle concentration as GNBs was applied for direct comparison. The ODs were then recorded with a commercial HG-8 strip reader. Figure $1 \mathrm{~d}$ also exhibits the size-dependent enhancement in OD values for GNBs, which are consistent with the change trend of absorbance against the GNB sizes. The OD values of $\mathrm{GNB}_{94}, \mathrm{GNB}_{129}$, and $\mathrm{GNB}_{237}$ presented a 1.24-, 2.46-, and 4.08-fold enhancement compared with the $\mathrm{AuNP}_{40}$, respectively. These results illustrated that the assembled GNBs can provide remarkably enhanced colorimetric signal intensity on the test strip, thus contributing to the improvement of LFIA sensitivity.

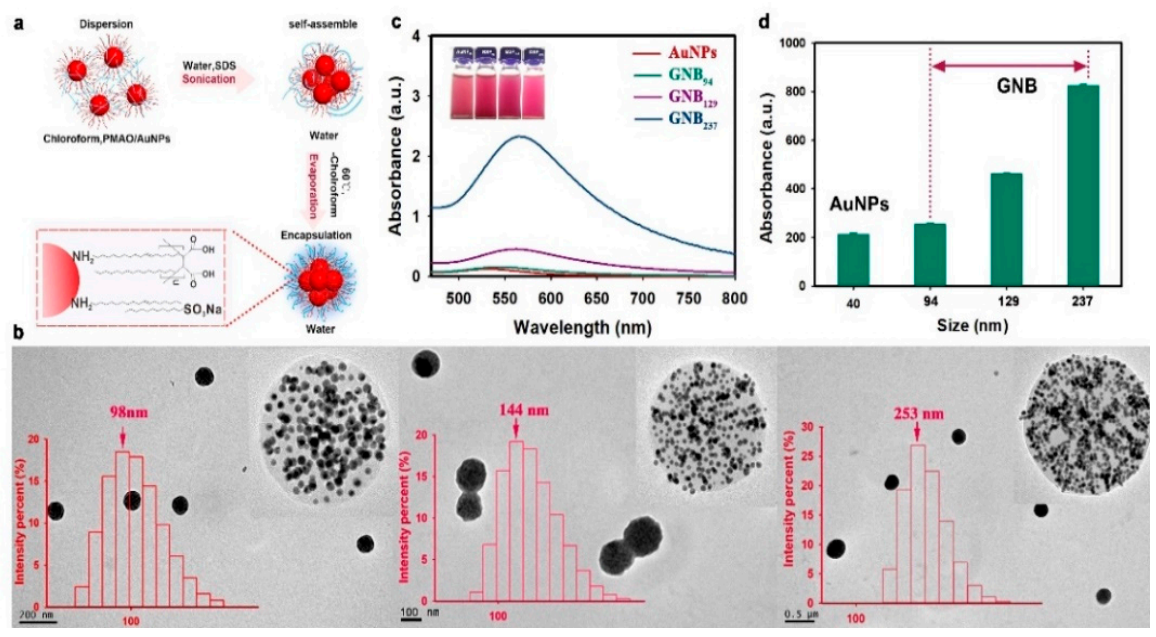

Figure 1. (a) The synthetic route of the designed GNBs. (b) TEM images and DLS measurement. (c) UV-vis absorption spectra of $\mathrm{GNB}_{94}, \mathrm{GNB}_{129}, \mathrm{GNB}_{237}$, and $\mathrm{AuNP}_{40}$. (d) Comparison of the OD values by spraying the $\mathrm{GNB}_{94}, \mathrm{GNB}_{129}, \mathrm{GNB}_{237}$, and $\mathrm{AuNP}_{40}$ on the $\mathrm{NC}$ membrane as the $\mathrm{T}$ lines at the same molar concentrations. 


\subsection{Detection Principle and Optimization of GNB-LFIA}

Analogous to traditional competitive LFIA, the developed GNB-LFIA shares the same detection principle (Scheme 1). In the absence of $\mathrm{FB}_{1}$, the $\mathrm{GNB}-\mathrm{mAb}$ probes were captured by the $\mathrm{BSA}-\mathrm{FB}_{1}$ conjugates to produce a clear red band at the $\mathrm{T}$ line. On the contrary, the GNB- $m A b$ probes first specifically recognized and captured the target $\mathrm{FB}_{1}$ from the sample solution in the presence of $\mathrm{FB}_{1}$ to form the $\mathrm{GNB}-\mathrm{mAb}-\mathrm{FB}_{1}$ complex, thus resulting in the decreased capture of GNB-mAbs at the T line. Consequently, the red band at the T line markedly decreased and disappeared. Thus, an inverse proportional relationship between the colored intensity at the $\mathrm{T}$ zone, that is, $\mathrm{OD}_{\mathrm{T}}$, and the $\mathrm{FB}_{1}$ concentration was obtained, which provided the possibility for $\mathrm{FB}_{1}$ quantitation. The presence of red band at the $\mathrm{C}$ line signifies the validity of the GNB-LFIA test strip. The $O D_{C}$ value was applied as a reference to enable a reliable signal output by using the $\mathrm{OD}_{\mathrm{T}} / \mathrm{OD}_{\mathrm{C}}$ ratio.

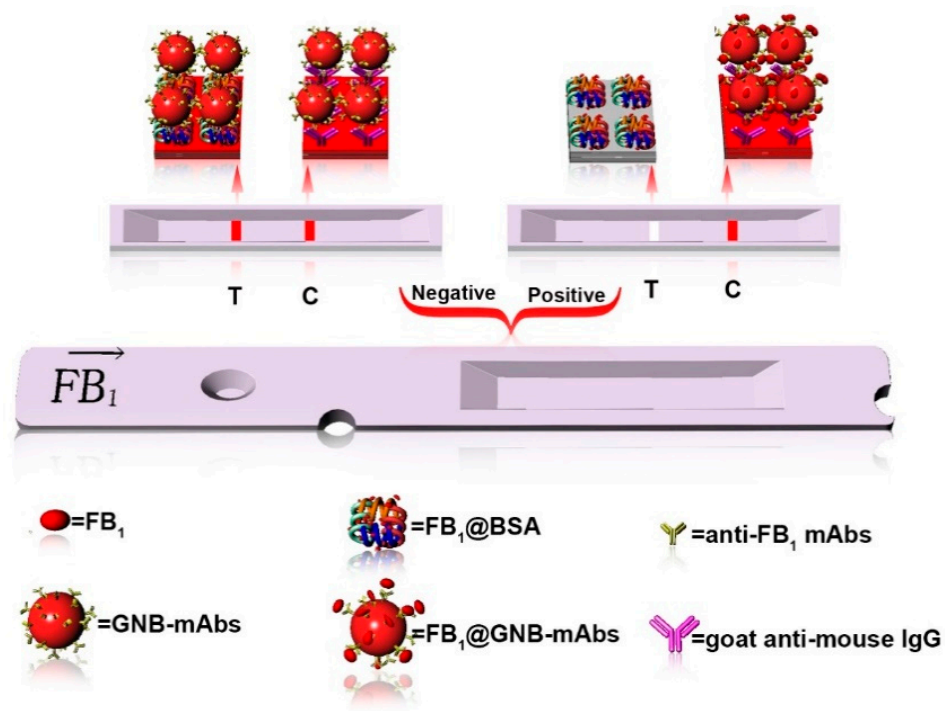

Scheme 1. Schematic illustration of the competitive GNB-LFIA for $\mathrm{FB}_{1}$ detection.

At present, the commonly used strategies for enhancing the detection sensitivity of competitive LFIA mainly include the following several aspects: (i) lowering the affinity of antibody to competing antigens; (ii) decreasing the amount of analytical antibody on the label; (iii) improving the signal intensity of the labeling probes; (iv) increasing the immunoreaction efficiency between the labeling probes and the antigen immobilized on the $\mathrm{T}$ line. The latter two approaches have attracted extensive research in recent years compared with the first method, which is often hard to perform for a pair of given antigen and antibody. In general, the signal intensity of the labeling probe is directly related to the probe size. For example, the absorbance and OD value increased with the increase in the GNB size. Such increment is theoretically beneficial to the improvement of the LFIA sensitivity. Nevertheless, the probe diffusion at the $\mathrm{T}$ line decreased with the increase in the probe size and reduced the immunoreaction efficiency, thus leading to sensitivity deterioration. The above-mentioned analysis manifested that the labeling probe with an appropriate size is crucial for the enhancement of the LFIA sensitivity. Thus, in this work, we first investigated the influence of the GNB size on the detection sensitivity of competitive LFIA. Several key factors, including the $\mathrm{pH}$ value, EDC concentration, and labeling concentration of anti- $\mathrm{FB}_{1} \mathrm{mAbs}$, that affect the conjugation efficiency of antibody were systematically studied and optimized to obtain the three best GNB-mAb probes. The $\mathrm{OD}_{\mathrm{T}}$ value obtained using the $\mathrm{FB}_{1}$-negative sample and the competition inhibition rates $\left(\left(1-\mathrm{B} / \mathrm{B}_{0}\right) \times 100 \%\right)$ obtained using the $\mathrm{FB}_{1}$-positive sample $(20 \mathrm{ng} / \mathrm{mL})$ were used to screen the optimum conditions. The results in Figures S2-S4 show that the optimal combinations are as follows: $\mathrm{pH} 6.0$ for the three GNBs, EDC concentration of $0.625 \mu \mathrm{g} / \mathrm{mL}$ for $\mathrm{GNB}_{94}$ and $\mathrm{GNB}_{129}$, and $1.25 \mu \mathrm{g} / \mathrm{mL}$ for $\mathrm{GNB}_{237}$; anti- $\mathrm{FB}_{1} \mathrm{mAb}$ concentration of 
$2.14 \mu \mathrm{g}$ per pmol for $\mathrm{GNB}_{94}, 7.02 \mu \mathrm{g}$ for per pmol $\mathrm{GNB}_{129}$, and $36.8 \mu \mathrm{g}$ per pmol $\mathrm{GNB}_{237}$. Under these conditions, the appropriate $\mathrm{OD}_{\mathrm{T}}$ values were simultaneously obtained by using the blank sample and the highest inhibition rates for $20 \mathrm{ng} / \mathrm{mL} \mathrm{FB}_{1}$. Further optimizations

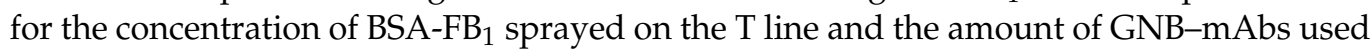
in each strip were completed. The result in Tables S2-S4 revealed that the optimal selections

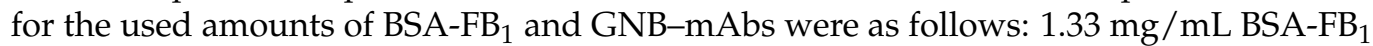
and $0.66 \mathrm{fmol} \mathrm{GNB}-\mathrm{mAbs}$ for GNB ${ }_{94}$-LFIA, $1.33 \mathrm{mg} / \mathrm{mL} \mathrm{BSA}^{-F_{1}}$ and $0.34 \mathrm{fmol} \mathrm{GNB}-$ $\mathrm{mAbs}$ for $\mathrm{GNB}_{129}$-LFIA, and $1.33 \mathrm{mg} / \mathrm{mL}$ BSA-FB 1 and $0.18 \mathrm{fmol} \mathrm{GNB}-\mathrm{mAbs}$ for $\mathrm{GNB}_{237-}$ LFIA. Subsequently, the immunological kinetic analysis was performed by recording the changes in the $\mathrm{OD}_{\mathrm{T}} / \mathrm{OD}_{\mathrm{C}}$ value against the immunoreaction time after running the strip using a PB saline (PBS) buffer containing the desired GNB-mAbs during a $30 \mathrm{~min}$ observation. Figure $\mathrm{S} 5$ shows that the $\mathrm{OD}_{\mathrm{T}} / \mathrm{OD}_{\mathrm{C}}$ values for the three GNB-LFIA strips reached a plateau after $15 \mathrm{~min}$ of immunoreaction. This finding suggests that no significant difference exists in the immunoreaction kinetics at different sizes of GNBs. Thus, $15 \mathrm{~min}$ was selected as the optimal signal interpretation time for three GNB-LFIA strips.

Under the optimized condition, the detection performance of three GNB-LFIA strips was evaluated by simultaneously measuring a series of $\mathrm{FB}_{1}$-spiked PBS solutions with different target concentrations ranging from $0 \mathrm{ng} / \mathrm{mL}$ to $1000 \mathrm{ng} / \mathrm{mL}$ by using the developed three GNB-LFIA strips. Figure 2 a shows the strip photographs obtained at different $\mathrm{FB}_{1}$ concentrations. The results indicated that the cutoff values representing the concentrations of $\mathrm{FB}_{1}$ that cause no color on the $\mathrm{T}$ line observed by the naked eye were $500 \mathrm{ng} / \mathrm{mL}$ for $\mathrm{GNB}_{94^{-}}$ LFIA, $125 \mathrm{ng} / \mathrm{mL}$ for $\mathrm{GNB}_{129}$-LFIA, and $500 \mathrm{ng} / \mathrm{mL}$ for $\mathrm{GNB}_{237}$-LFIA [6,39]. Figure $2 \mathrm{~b}$ presents the concentration-response relationships from the three GNB-LFIA strips. The figure exhibits the similar concentration-dependent decrease in the $\mathrm{B} / \mathrm{B}_{0} \times 100 \%$ for the three strips. The competitive inhibition (IC) curves for the three GNB-LFIA strips were further constructed by plotting the $\mathrm{B} / \mathrm{B}_{0} \times 100 \%$ against the logarithmic $\mathrm{FB}_{1}$ concentration. Figure $2 \mathrm{c}$ demonstrates that the $\mathrm{GNB}_{129}$-LFIA achieved a low $\mathrm{IC}_{50}$ value of $13.07 \mathrm{ng} / \mathrm{mL}$, which is 2.32- and 1.85-fold lower than those of $\mathrm{GNB}_{94}-\mathrm{LFIA}\left(\mathrm{IC}_{50}: 30.44 \mathrm{ng} / \mathrm{mL}\right.$ ) and $\mathrm{GNB}_{237}$-LFIA ( $\left(\mathrm{IC}_{50}: 24.22 \mathrm{ng} / \mathrm{mL}\right.$ ). The $\mathrm{OD}_{\mathrm{T}}$ value of $\mathrm{GNB}_{237}$ in Figure $1 \mathrm{~d}$ is 1.66 -fold higher than that of $\mathrm{GNB}_{129}$. However, the $\mathrm{OD}_{\mathrm{T}}$ of $\mathrm{GNB}_{237}$-LFIA is 1.85-fold lower than that of $\mathrm{GNB}_{129}$-LFIA in terms of sensitivity. These results demonstrated that the GNB size is a critical factor in enhancing the LFIA sensitivity; only appropriately sized GNBs can provide enhanced target detection. The possible reasons are as follows. (1) The small-size GNBs exhibited insufficient signal intensity, thus increasing the accumulated number of GNB at the T line for decreased competition and poor sensitivity; (2) the oversized GNBs displayed sufficient signal intensity but reduced diffusion and increased steric hindrance, causing low immunoreaction efficiency and sensitivity. Considering the high sensitivity, $\mathrm{GNB}_{129}$-LFIA was selected for all succeeding evaluation.
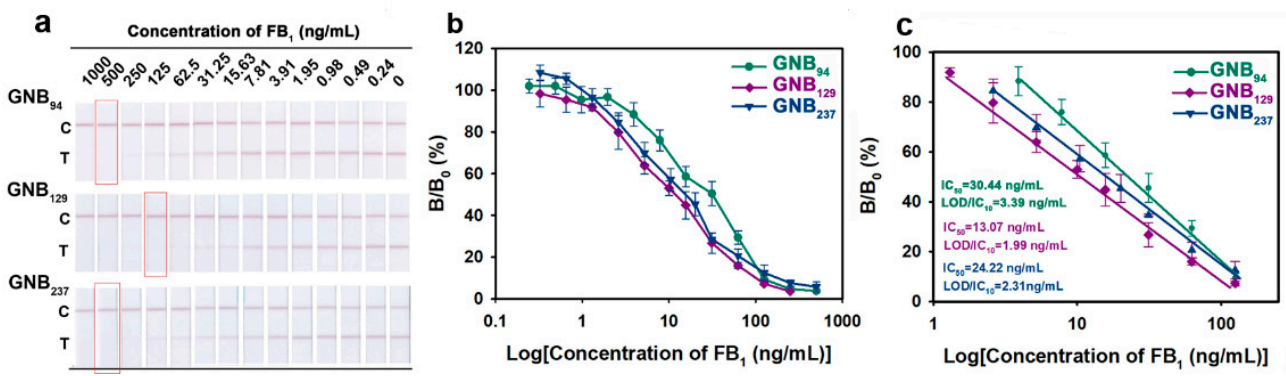

Figure 2. Effect of the GNB size on the detection sensitivity of competitive LFIA. (a) The prototypes of three GNB-LFIA strips responding to varying $\mathrm{FB}_{1}$ concentrations. (b) The relationship analyses for three GNB-LFIAs between the $\mathrm{B} / \mathrm{B}_{0} \times 100 \%$ value and the $\mathrm{FB}_{1}$ concentration ranged from 0 to $1000 \mathrm{ng} / \mathrm{mL}$. (c) The linear dependence of three GNB-LFIA strips obtained by plotting the $\mathrm{B} / \mathrm{B}_{0} \times 100 \%$ against the logarithmic $\mathrm{FB}_{1}$ concentration. 
Previous studies demonstrated that the $\mathrm{pH}$ and methanol content in the reaction system are key parameters that could influence the sensitivity and reproducibility of LFIA by disturbing the antigen-antibody interaction. Thus, a careful investigation about the effects of $\mathrm{pH}$ and methanol concentration on the sensitivity of $\mathrm{GNB}_{129}$-LFIA was completed (Figure $3 \mathrm{a}, \mathrm{b}$ ). Results showed the optimized $\mathrm{pH}$ and methanol concentration at 6.0 and $5 \%$, respectively.
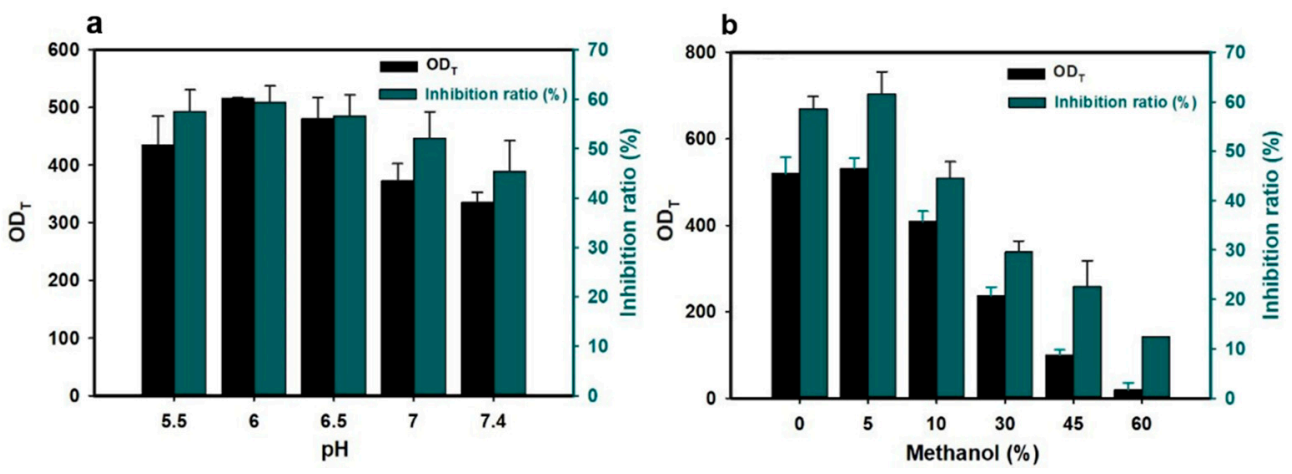

Figure 3. Effect of the $\mathrm{pH}$ value (a) and methanol concentration (b) in the reaction system on the $\mathrm{OD}_{\mathrm{T}}$ value using the blank corn extraction solution and the competitive inhibition rate using the $\mathrm{FB}_{1}$-spiked corn extraction solution $(20 \mathrm{ng} / \mathrm{mL})$. The competitive inhibition rate was defined as $\left(1-\mathrm{B} / \mathrm{B}_{0}\right) \times 100 \%$, where $\mathrm{B}_{0}$ and $\mathrm{B}$ represent the $\mathrm{OD}_{\mathrm{T}} / \mathrm{OD}_{\mathrm{C}}$ value of the $\mathrm{FB}_{1}$-negative and positive sample, respectively.

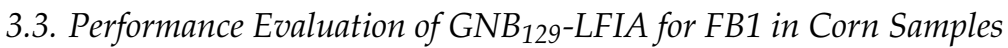

Under the developed conditions, the calibration curve of the $\mathrm{GNB}_{129}$-LFIA strip was constructed by plotting $\mathrm{B} / \mathrm{B}_{0} \times 100 \%$ against the logarithmic concentration of $\mathrm{FB}_{1}$ in spiked corn samples. Figure 4 a shows the strip photographs obtained at different $\mathrm{FB}_{1}$ concentrations in real corn sample detection. Figure $4 \mathrm{~b}$ presents that the $\mathrm{B} / \mathrm{B}_{0} \times 100 \%$ value decreased as the $\mathrm{FB}_{1}$ concentration increased. An excellent linear dependence was observed between the two factors at $\mathrm{FB}_{1}$ concentration ranging from $3.9 \mathrm{ng} / \mathrm{mL}$ to $125 \mathrm{ng} / \mathrm{mL}$ with an $\mathrm{R}^{2}$ of 0.9931 . The regression equation can be described as $y=-21.25 \ln (x)+101.83$. The $\mathrm{IC}_{50}$ value for $\mathrm{FB}_{1}$ was as low as $11.27 \mathrm{ng} / \mathrm{mL}$, which is 3.82-fold lower than that of the conventional AuNP 40 -based LFIA strip $\left(\mathrm{IC}_{50}=43.04 \mathrm{ng} / \mathrm{mL}\right.$ ) (Figure $\mathrm{S6}$ and S7), and the LOD of $\mathrm{GNB}_{129}$-LFIA was as low as $1.79 \mathrm{ng} / \mathrm{mL}$, according to $10 \% \mathrm{FB}_{1}$ competitive inhibition concentration, which was 2.89-flod lower than $\mathrm{AuNP}_{40}$-based LFIA [39]. The specificity analysis in Figure $4 c$ suggested the excellent selectivity of this $\mathrm{GNB}_{129}$-LFIA strip for $\mathrm{FB}_{1}$ against other common mycotoxins, including $\mathrm{AFB}_{1}, \mathrm{AFB}_{2}, \mathrm{OTA}, \mathrm{DON}, \mathrm{AFG}, \mathrm{CIT}$, and $\mathrm{ZEN}$ at the concentration of $1 \mu \mathrm{g} / \mathrm{mL}$. The accuracy and precision analysis of this strip method was performed by calculating the intra- and inter-assay recoveries and coefficients of variation $(\mathrm{CV})$ of the five $\mathrm{FB}_{1}$-spiked corn samples with $\mathrm{FB}_{1}$ concentrations of $10,5,2$, 1 , and $0.5 \mathrm{mg} / \mathrm{kg}$. Table 1 illustrates that the average recoveries for intra- and inter-assay changed from $91.42 \%$ to $112.64 \%$, with the CV ranging from $5.16 \%$ to $15.6 \%$, demonstrating an acceptable accuracy and precision for $\mathrm{FB}_{1}$ quantification. The reliability of our method was further evaluated by detecting $\mathrm{FB}_{1}$ in 35 spiked corn samples. The detection results were then compared with the well-accepted $\mathrm{FB}_{1}$ ELISA kit method. The results in Figure $4 \mathrm{~d}$ revealed that a high linear dependence with an $R^{2}$ of 0.9695 was achieved between the two approaches. This finding suggests that the developed $\mathrm{GNB}_{129}$-LFIA strip is comparable to ELISA in terms of $\mathrm{FB}_{1}$ quantification. The proposed strip method is simple (no wash) and fast (15 min vs. 45 min for ELISA, in Figure S8) for the $\mathrm{FB}_{1}$ screening test. Compared with other previously reported LFIA methods for measuring $\mathrm{FB}_{1}$, the prepared $\mathrm{GNB}_{129}$-LFIA possesses an acceptable sensitivity and quantitative linear range (Table S5). 
a

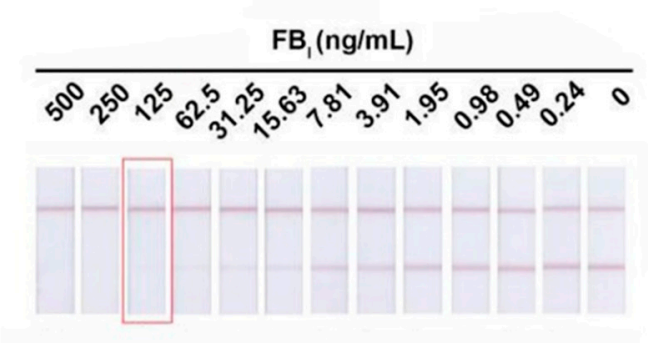

C

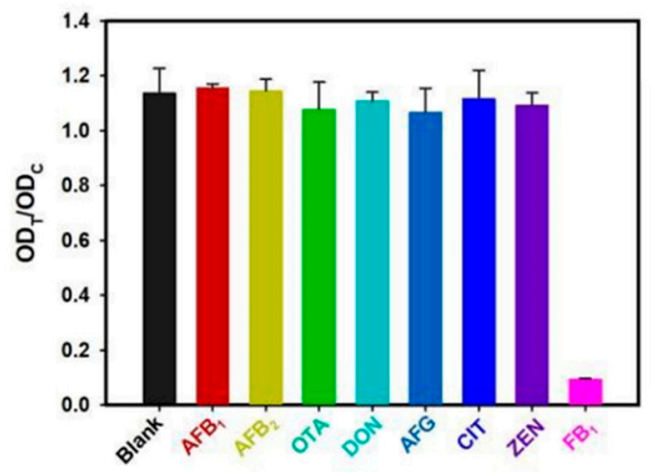

b

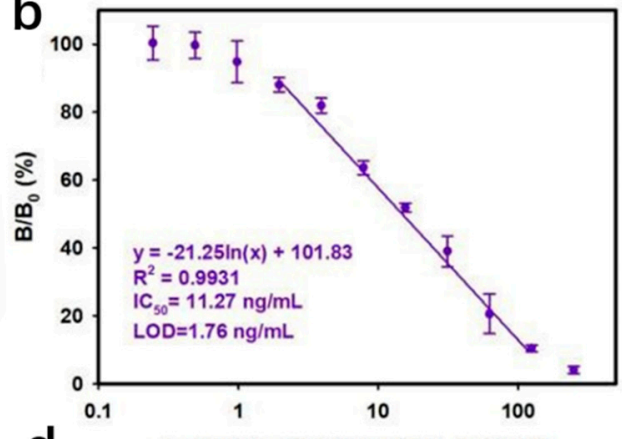

d

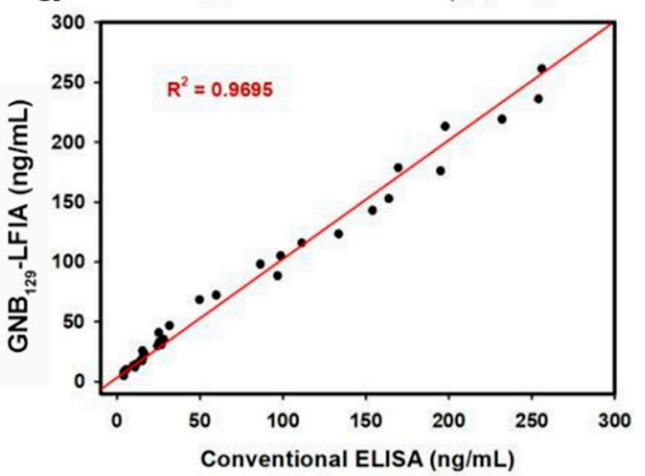

Figure 4. The performance evaluation for the $\mathrm{GNB}_{129}$-LFIA strips for $\mathrm{FB}_{1}$ detection in corn sample. (a) The prototypes of $\mathrm{GNB}_{129}$-LFIA strips responding to varying $\mathrm{FB}_{1}$ concentrations in real corn sample detection. (b) The competitive inhibition curve of the $\mathrm{GNB}_{129}$-LFIA constructed by plotting the $\mathrm{B} / \mathrm{B}_{0} \times 100 \%$ against the logarithm of $\mathrm{FB}_{1}$ concentration. (c) The selectivity of our method by detecting the response against other common mycotoxins. (d) The correlation analysis of the detection results between the $\mathrm{GNB}_{129}$-LFIA strip and the ELISA method in 35 real corn samples, with $\mathrm{FB}_{1}$ concentrations ranged from 1.5 to $267 \mathrm{ng} / \mathrm{mL}$.

Table 1. The accuracy and precision of the $\mathrm{GNB}_{129}$-LFIA method for $\mathrm{FB}_{1}$ detection in spiked corn samples.

\begin{tabular}{|c|c|c|c|c|c|c|}
\hline \multirow{2}{*}{$\begin{array}{c}\text { Spiked } \\
\text { Concentration } \\
\mathrm{FB}_{1}\left(\mathrm{mg} \mathrm{kg}^{-1}\right)\end{array}$} & \multicolumn{3}{|c|}{ Intra-Assay Precision } & \multicolumn{3}{|c|}{ Inter-Assay Precision } \\
\hline & $\begin{array}{c}\text { Detected } \\
\text { Concentration }\end{array}$ & $\mathrm{CV}$ & Recovery (\%) & $\begin{array}{c}\text { Detected } \\
\text { Concentration }\end{array}$ & $\mathrm{CV}$ & Recovery (\%) \\
\hline 10 & $9.78 \pm 1.52$ & 15.6 & 97.82 & $9.24 \pm 0.39$ & 5.16 & 92.43 \\
\hline 5 & $5.63 \pm 0.39$ & 6.96 & 112.64 & $5.23 \pm 0.47$ & 7.37 & 112.5 \\
\hline 2 & $1.94 \pm 0.24$ & 12.51 & 97.01 & $2.18 \pm 0.21$ & 9.80 & 108.97 \\
\hline 1 & $0.97 \pm 0.06$ & 7.12 & 96.93 & $0.91 \pm 0.09$ & 9.40 & 91.42 \\
\hline 0.5 & $0.48 \pm 0.02$ & 7.62 & 95.97 & $0.447 \pm 0.03$ & 5.30 & 89.41 \\
\hline
\end{tabular}

a The assay was carried out in triplicates on the same day. ${ }^{\mathrm{b}}$ The assay was performed on three consecutive days.

\section{Conclusions}

In this work, novel self-assembled GNBs were successfully synthesized by encapsulating hydrophobic AuNPs into a polymer matrix by using the emulsion-based self-assembly strategy. The obtained GNBs possessed a remarkably enhanced optical absorption, which is mainly attributed to the collective molar extinctions of numerous AuNPs embedded in GNBs. Using the designed GNBs as signal reporter, we further demonstrated that the developed GNB-LFIA can achieve the best detection for $\mathrm{FB}_{1}$ in corn samples with an $\mathrm{IC}_{50}$ of as low as $11.27 \mathrm{ng} / \mathrm{mL}$ under the optimal GNB size of $129 \mathrm{~nm}$. The $\mathrm{IC}_{50}$ value of our $\mathrm{GNB}_{129}$-LFIA was 3.82 times better than that of conventional AuNP 40 -LFIA. This work proves the feasibility of using the amplified GNBs as alternative probes to improve the 
sensitivity of competitive LFIA. This study also provides a universal strategy to achieve enhanced target detection on conventional LFIA platform.

Supplementary Materials: The following are available online at https:/ / www.mdpi.com/article/10 $.3390 /$ foods10071488/s1.

Author Contributions: Conceptualization, X.C., L.H., X.H. and Y.X.; Data curation, X.C. and H.D.; Formal analysis, X.M. and T.M.; Funding acquisition, X.H. and Y.X.; Investigation, T.M., Y.L. (Yuankui Leng), J.Y. and Y.L. (Yu Li); Methodology, X.C., X.M., T.M., Y.L. (Yuankui Leng), L.H., H.D., J.Y., Y.L. (Yu Li) and X.H.; Project administration, X.H. and Y.X.; Supervision, X.H. and Y.X.; Writingoriginal draft, X.C.; Writing-review \& editing, X.H. and Y.X. All authors have read and agreed to the published version of the manuscript.

Funding: This research was supported by the National Key Research and Development Program of China (2018YFC1602505), the National Natural Science Foundation of China (32001788), the Interdisciplinary Innovation Fund of Natural Science, Nanchang University (9166-27060003-ZD01), and the Opening Fund of Jiangsu Key Laboratory for Food Quality and Safety-State Key Laboratory Cultivation Base, Ministry of Science and Technology (028074911709).

Institutional Review Board Statement: Not applicable.

Informed Consent Statement: Not applicable.

Conflicts of Interest: The authors declare no conflict of interest.

\section{References}

1. Loynachan, C.N.; Thomas, M.R.; Gray, E.R.; Richards, D.A.; Kim, J.; Miller, B.S. Platinum Nanocatalyst Amplification: Redefining the Gold Standard for Lateral Flow Immunoassays with Ultrabroad Dynamic Range. ACS Nano 2018, 12, 279-288. [CrossRef] [PubMed]

2. Pan, M.; Ma, T.; Yang, J.; Li, S.; Liu, S.; Wang, S. Development of Lateral Flow Immunochromatographic Assays Using Colloidal $\mathrm{Au}$ Sphere and Nanorods as Signal Marker for the Determination of Zearalenone in Cereals. Foods 2020, 3, 281. [CrossRef]

3. Zhou, Y.; Ding, L.; Wu, Y.; Huang, X.; Lai, W.; Xiong, Y. Emerging Strategies to Develop Sensitive AuNP-Based ICTS Nanosensors. TrAC Trends Anal. Chem. 2019, 112, 147-160. [CrossRef]

4. Luo, K.; Hu, L.; Guo, Q.; Wu, C.; Wu, S.; Liu, D. Comparison of 4 Label-Based Immunochromatographic Assays for the Detection of Escherichia Coli O157:H7 in Milk. J. Dairy Sci. 2017, 100, 5176-5187. [CrossRef] [PubMed]

5. Khlebtsov, B.N.; Tumskiy, R.S.; Burov, A.M.; Pylaev, T.E.; Khlebtsov, N.G. Quantifying the Numbers of Gold Nanoparticles in the Test Zone of Lateral Flow Immunoassay Strips. ACS Appl. Nano Mater. 2019, 2, 5020-5028. [CrossRef]

6. Duan, H.; Huang, X.; Shao, Y.; Zheng, L.; Guo, L.; Xiong, Y. Size-Dependent Immunochromatographic Assay with Quantum Dot Nanobeads for Sensitive and Quantitative Detection of Ochratoxin A in Corn. Anal. Chem. 2017, 89, 7062-7068. [CrossRef]

7. Zhao, P.; Wu, Y.; Zhu, Y.; Yang, X.; Jiang, X.; Xiao, J. Upconversion Fluorescent Strip Sensor for Rapid Determination of Vibrio Anguillarum. Nanoscale 2014, 6, 3804-3809. [CrossRef] [PubMed]

8. Sun, Q.; Zhao, G.; Dou, W. An Optical and Rapid Sandwich Immunoassay Method for Detection of Salmonella Pullorum and Salmonella Gallinarum Based on Immune Blue Silica Nanoparticles and Magnetic Nanoparticles. Sens. Actuators B 2016, 226, 69-75. [CrossRef]

9. Huang, Z.; Hu, S.; Xiong, Y.; Wei, H.; Xu, H.; Duan, H.; Lai, W. Application and Development of Superparamagnetic Nanoparticles in Sample Pretreatment and Immunochromatographic Assay. TrAC Trends Anal. Chem. 2019, 114, 151-170. [CrossRef]

10. Dement'eva, O.; Naumova, K.; Zhigletsova, S.; Klykova, M.; Somov, A.; Dunaytsev, I.; Senchikhin, I.; Volkov, V.; Rudoy, V. Drug-Templated Mesoporous Silica Nanocontainers with Extra High Payload and Controlled Release Rate. Colloids Surf. B. 2020, 185, 110577. [CrossRef]

11. Gómez-Hens, A.; Manuel Fernández-Romero, J. The Role of Liposomes in Analytical Processes. TrAC Trends Anal. Chem. 2005, 24, 9-19. [CrossRef]

12. Slowing, I.I.; Trewyn, B.G.; Giri, S.; Lin, V.S.Y. Mesoporous Silica Nanoparticles for Drug Delivery and Biosensing Applications. Adv. Funct. Mater. 2007, 17, 1225-1236. [CrossRef]

13. Hofmann, C.; Duerkop, A.; Baeumner, A.J. Nanocontainers for Analytical Applications. Angew. Chem. Int. Ed. 2019, 58, 12840-12860. [CrossRef]

14. Bhushan, B.; Kumar, S.U.; Matai, I.; Sachdev, A.; Dubey, P.; Gopinath, P. Ferritin Nanocages: A Novel Platform for Biomedical Applications. J. Biomed. Nanotechnol. 2014, 10, 2950-2976. [CrossRef]

15. Feng, A.; Yuan, J. Smart Nanocontainers: Progress on Novel Stimuli-Responsive Polymer Vesicles. Macromol. Rapid Commun. 2014, 35, 767-779. [CrossRef] [PubMed]

16. Li, W.; Wu, X.; Han, N.; Chen, J.; Qian, X.; Deng, Y.; Tang, W.; Chen, Y. MOF-Derived Hierarchical Hollow ZnO Nanocages with Enhanced Low-Concentration VOCs Gas-Sensing Performance. Sens. Actuators B 2016, 225, 158-166. [CrossRef] 
17. Bi, J.; Wang, H.; Kamal, T.; Zhu, B.-W.; Tan, M. A Fluorescence Turn-Off-On Chemosensor Based on Carbon Nanocages for Detection of Ascorbic Acid. RSC Adv. 2017, 7, 30481-30487. [CrossRef]

18. Misson, M.; Zhang, H.; Jin, B. Nanobiocatalyst Advancements and Bioprocessing Applications. J. R. Soc. Interface 2015, 12, 20140891. [CrossRef] [PubMed]

19. Broz, P.; Driamov, S.; Ziegler, J.; Ben-Haim, N.; Marsch, S.; Meier, W.; Hunziker, P. Toward Intelligent Nanosize Bioreactors: A pH-Switchable, Channel-Equipped, Functional Polymer Nanocontainer. Nano Lett. 2006, 6, 2349-2353. [CrossRef] [PubMed]

20. Li, J.; Lu, S.; Huang, H.; Liu, D.; Zhuang, Z.; Zhong, C. ZIF-67 as Continuous Self-Sacrifice Template Derived NiCo ${ }_{2} \mathrm{O}_{4} / \mathrm{Co}_{2} \mathrm{~N}_{-}$ CNTs Nanocages as Efficient Bifunctional Electrocatalysts for Rechargeable Zn-Air Batteries. ACS Sustain. Chem. Eng. 2018, 6, 10021-10029. [CrossRef]

21. Trantidou, T.; Friddin, M.; Elani, Y.; Brooks, N.J.; Law, R.V.; Seddon, J.M.; Ces, O. Engineering Compartmentalized Biomimetic Micro- and Nanocontainers. ACS Nano 2017, 11, 6549-6565. [CrossRef] [PubMed]

22. Wang, Y.; Han, P.; Xu, H.; Wang, Z.; Zhang, X.; Kabanov, A.V. Photocontrolled Self-Assembly and Disassembly of Block Ionomer Complex Vesicles: A Facile Approach toward Supramolecular Polymer Nanocontainers. Langmuir 2010, 26, 709-715. [CrossRef]

23. Haase, M.F.; Grigoriev, D.O.; Möhwald, H.; Shchukin, D.G. Development of Nanoparticle Stabilized Polymer Nanocontainers with High Content of the Encapsulated Active Agent and Their Application in Water-Borne Anticorrosive Coatings. Adv. Mater. 2012, 24, 2429-2435. [CrossRef]

24. Yagai, S.; Karatsu, T.; Kitamura, A. Photocontrollable Self-Assembly. Chem. Eur. J. 2005, 11, 4054-4063. [CrossRef] [PubMed]

25. O'Neil, C.P.; Suzuki, T.; Demurtas, D.; Finka, A.; Hubbell, J.A. A Novel Method for the Encapsulation of Biomolecules into Polymersomes via Direct Hydration. Langmuir 2009, 25, 9025-9029. [CrossRef]

26. Lo, H.; Ponticiello, M.S.; Leong, K.W. Fabrication of Controlled Release Biodegradable Foams by Phase Separation. Tissue Eng. 1995, 1, 15-28. [CrossRef] [PubMed]

27. Capadona, J.R.; Van Den Berg, O.; Capadona, L.A.; Schroeter, M.; Rowan, S.J. A Versatile Approach for the Processing of Polymer Nanocomposites with Self-Assembled Nanofibre Templates. Nat. Nanotechnol. 2007, 2, 765-769. [CrossRef]

28. Messager, L.; Burns, J.R.; Kim, J.; Cecchin, D.; Hindley, J.; Pyne, A.L.; Gaitzsch, J.; Battaglia, G.; Howorka, S. Biomimetic Hybrid Nanocontainers with Selective Permeability. Angew. Chem. 2016, 128, 11272-11275. [CrossRef]

29. Ren, M.; Xu, H.; Huang, X.; Kuang, M.; Xiong, Y.; Xu, H.; Xu, Y.; Chen, H.; Wang, A. Immunochromatographic Assay for Ultrasensitive Detection of Aflatoxin B1 in Maize by Highly Luminescent Quantum Dot Beads. ACS Appl. Mater. Interfaces 2014, 6, 14215-14222. [CrossRef]

30. Chen, X.; Leng, Y.; Hao, L.; Duan, H.; Yuan, J. Self-Assembled Colloidal Gold Superparticles to Enhance the Sensitivity of Lateral Flow Immunoassays with Sandwich Format. Theranostics 2020, 10, 3737-3748. [CrossRef]

31. Zhan, L.; Guo, S.-Z.; Song, F.; Gong, Y.; Xu, F.; Boulware, D.R.; McAlpine, M.C.; Chan, W.C.W.; Bischof, J.C. The Role of Nanoparticle Design in Determining Analytical Performance of Lateral Flow Immunoassays. Nano Lett. 2017, 17, 7207-7212. [CrossRef]

32. Petrarca, M.H.; Rodrigues, M.I.; Rossi, E.A.; de Sylos, C.M. Optimisation of A Sample Preparation Method for the Determination of Fumonisin B1 in Rice. Food Chem. 2014, 158, 270-277. [CrossRef] [PubMed]

33. Mexía-Salazar, A.L.; Hernández-López, J.; Burgos-Hernández, A.; Cortez-Rocha, M.O.; Castro-Longoria, R.; Ezquerra-Brauer, J.M. Role of Fumonisin B1 on the Immune System, Histopathology, and Muscle Proteins of White Shrimp (Litopenaeus Vannamei). Food Chem. 2008, 110, 471-479. [CrossRef] [PubMed]

34. Wang, Z.; Li, H.; Li, C.; Yu, Q.; Shen, J.; De Saeger, S. Development and Application of a Quantitative Fluorescence-Based Immunochromatographic Assay for Fumonisin B1 in Maize. J. Agric. Food Chem. 2014, 62, 6294-6298. [CrossRef] [PubMed]

35. Anttila, A.; Bhat, R.V.; Bond, J.A.; Borghoff, S.J.; Bosch, F.X.; Carlson, G.P.; Castegnaro, M.; Cruzan, G.; Gelderblom, W.C.; Hass, U. IARC Monographs on the Evaluation of Carcinogenic Risks to Humans: Some Traditional Herbal Medicines, Some Mycotoxins, Naphthalene and Styrene. In IARC Monographs on the Evaluation of Carcinogenic Risks to Humans; IARC Press: Lyon, France, 2002; Volume 82.

36. Hiramatsu, H.; Osterloh, F.E. A Simple Large-Scale Synthesis of Nearly Monodisperse Gold and Silver Nanoparticles with Adjustable Sizes and with Exchangeable Surfactants. Chem. Mater. 2004, 16, 2509-2511. [CrossRef]

37. Chen, X.; Liang, Y.; Zhang, W.; Leng, Y.; Xiong, Y. A Colorimetric Immunoassay Based on Glucose Oxidase-Induced AuNP Aggregation for Fumonisin B1. Talanta 2018, 186, 29-35. [CrossRef]

38. Ji, Y.; Ren, M.; Li, Y.; Huang, Z.; Shu, M.; Yang, H.; Xiong, Y.; Xu, Y. Detection of Aflatoxin B1 with Immunochromatographic Test Strips: Enhanced Signal Sensitivity using Gold Nanoflowers. Talanta 2015, 142, 206-212. [CrossRef]

39. Duan, H.; Chen, X.; Xu, W.; Fu, J.; Xiong, Y.; Wang, A. Quantum-Dot Submicrobead-Based Immunochromatographic Assay for Quantitative and Sensitive Detection of Zearalenone. Talanta 2015, 132, 126-131. [CrossRef] [PubMed] 